\title{
Commentary \\ The Challenge of Addressing Obesity: Moving to the Extremes
}

\author{
Glenn Laverack \\ Centre for Health Promotion Research, Syddansk Universitet, Niels Bohrs Vej 9-10, 6700 Esbjerg, Denmark; \\ grlavera@hotmail.com
}

Received: 6 July 2018; Accepted: 8 August 2018; Published: 10 August 2018

\begin{abstract}
Obesity is preventable but there is still no single model for prevention and no country has managed to convincingly reverse the growing trend, estimated in 2016 to be 650 million adults. Globally, the increase in obesity will have catastrophic consequences for the economy and for population health. 'Desperate times breed desperate measures' and this paper outlines the shift that many governments are being forced to make to halt the growth of obesity. Moving to the extremes means that the planning and coordination of strategies places an equal emphasis on top-down (policy, regulation, and taxation) and bottom-up (local actions, self-help groups, volunteerism) interventions. There is still an important role for communication, the middle-ground between the extremes of bottom-up and top-down, but governments must use 'power-over' measures to take control of the causes of obesity. Bringing the public with them will be crucial to success and can be achieved through a sharing of resources, a 'power-with', to combine top-down and bottom-up interventions in the future.
\end{abstract}

Keywords: obesity; policy framework; community-centred; power; behaviour change; public health

\section{Global Obesity}

Overweight and obesity are defined as abnormal or excessive fat accumulation that may impair health [1]. In 2016, more than 1.9 billion adults, 18 years and older, were considered to be overweight, with over 650 million having obesity. It has been predicted that there will be 65 million more adults with obesity in the USA and 11 million more adults with obesity in the UK by the year 2030 and that this will result in an additional 8.5 million cases of diabetes and 7.3 million cases of heart disease in the USA and UK combined. The medical costs associated with the treatment of these preventable diseases are estimated to increase by $\$ 48$ to 66 billion/year in the USA and by $£ 2$ billion/year in the UK by 2030. Over 340 million children and adolescents aged 5-19 were also overweight or obese in 2016 and childhood obesity is one of the most rapidly growing global public health challenges [2]. The fundamental cause of obesity is thought to be an energy imbalance between the amount of calories consumed and calories expended. There has been an increased intake of energy-dense foods and an increase in sedentary behaviours and physical inactivity due to the sedentary nature of many forms of work and leisure and urbanization. Changes in dietary and physical activity patterns are often the result of environmental and societal changes associated with economic development and the lack of supportive policies in sectors such as transport, the environment, and food processing. The purpose of this paper is to support the shift that many governments will have to make to halt the growth of obesity by moving to the extremes of top-down (policy, regulation, and taxation) and bottom-up (local actions, self-help groups, volunteerism) interventions. The role for communication, the middle-ground between the extremes, will continue but governments must take a more stringent position and bring the public with them to address obesity. 


\section{Why We Are Where We Are}

Obesity is preventable but no comprehensive approach for prevention has emerged and no one country has managed to convincingly halt the growing trend. It is therefore worth asking why we are where we are. Public health programs have been designed to be professionally driven, top-down, pre-packaged and with a bio-medical approach. Top-down is interpreted here as when health interventions are decided by the top structures, usually an outside agency or health worker, and are delivered 'down' to the intended beneficiaries. The top-down approach has used epidemiological data to address a population-based lifestyle agenda including physical inactivity, nutrition and smoking [3]. The lifestyle agenda has proven to be attractive to governments because it promised easily quantifiable results within a relatively short time frame for high prevalence health problems such as obesity [4] and offered cost-savings in healthcare services for people suffering from chronic diseases [5]. Despite the modest evidence for the success of the lifestyle agenda, it has remained a popular option because it offers the simple logic of behaviour change through education and motivational strategies that can be easily delivered in a program context [6]. However, addressing chronic disease involves the interplay of different risk factors and determinants including smoking, diet and sedentary behaviours, unemployment and stress. The lifestyle agenda has conveniently shifted the focus away from awkward political decisions that underlie these risk factors and determinants and which are rooted in poverty and health inequality [7]. The unintended consequences of these types of approach can be a preoccupation with weight loss among the general population, which can lead to stigma, body dissatisfaction, disordered eating and obesity surgery complications [8]. Public health approaches should acknowledge the complexity of obesity, for example, by incorporating it into a population approach to chronic disease prevention, possibly with less stigmatizing consequences. Public health approaches may by design continue to address individual-level issues but they must also address the broader determinants of health of chronic disease if they are to be effective.

\section{Modest Successes}

The modest successes of the top-down approach have been largely limited to higher socio-economic groups. In Australia, over the period 1998-2004 there was a 9\% decrease in smoking in the lowest quintile compared to a 35\% decrease in the highest quintile [9]. In Canada, over the period 2000-2005 a top-down program to increase physical activity in urban and rural communities found that $30 \%$ people had become more active whilst $14 \%$ had become less active. Significantly, the change in physical activity had occurred in the higher socio-economic groups with little or no effect on low socio-economic, adolescents, ethnic minorities, or indigenous people [10]. The top-down approach has relied heavily on strategies that use health education to raise awareness to bring about behaviour change with an emphasis on the responsibility of the individual. This is an approach that can lead to a 'victim-blaming' culture for not changing unhealthy lifestyles even though certain factors are beyond the control of the individual such as being made unemployed. Health education messaging is based on common sense and has remained unchanged for many decades, for example, in regard to 'clean living', involving daily physical exercise and good nutrition [11]. The modest successes of the top-down approach have not been because of the health issues it has chosen to address or the messages it chooses to communicate. It has been because of the way in has been delivered, resulting in low public participation, especially of marginalised groups, compromising long-term outcomes such as a reduction of obesity. One review, for example, found that obesity prevention programs showed limited evidence of effectiveness. There was a lack of upstream investment and an emphasis on individual-based programs that only resulted in short-term improvements relating to obesity prevention [12]. Bottom-up interventions that include people in the program design, implementation and evaluation were identified as being crucial to success by helping to ensure that people's needs are met. Bottom-up is interpreted here as approaches that assist people to identify their own needs and to communicate these 'up' to the top structures of planning and decision-making. 
The 'middle ground' of using behaviour change and motivational strategies to address obesity has also had modest successes and has failed to reverse the growing trend in obesity. Globally obesity continues to increase, and this will have catastrophic consequences for the economy and for population health. 'Desperate times breed desperate measures', and many governments will be forced to shift their approach to move to the two extremes in the absence of a viable model to halt the growth in obesity.

\section{Moving to the Extremes}

In Estonia, 89\% of school children drink sugar-sweetened beverages. The Estonian government has used a policy framework to reduce the consumption of sugar-sweetened drinks which are associated with increased energy intake and higher risks for poor oral health and weight gain. The strategy used a policy framework with four options: (1) regulation of food advertising; (2) labelling of sugar-sweetened beverages and raising awareness about their health effects; (3) school health promotion interventions and nutrition policies; and (4) imposing taxes on sugar-sweetened beverages, subsidizing other food groups, and substituting alternative beverages [13]. Power-over is interpreted here as an exercise of control in which people can be constrained and influenced by those that have 'power-over' them, both positively and negatively. Taxation, for example, on products such as sugar-sweetened beverages, is an exercise of power-over people's choices to promote a healthy lifestyle by moderating consumption. This is a top-down strategy in which the interventions are controlled by the government structures and delivered 'down' to the public, the intended beneficiaries. However, to be effective, top-down and bottom-up approaches must complement each other. It is not a question of either top-down or bottom-up, but a combination of both that will reach the goal of better health outcomes. Moving to the extremes means a framework that actively includes community-centred interventions alongside increased power-over measures such as regulation, health policy, and taxation. The government, with the power-over, can choose not to dominate but to form a relationship that will deliberately increase the other's level of control. This is interpreted here as a form of 'power-with', in which control and access to resources are shared with other partners such as communities through, for example, providing training and financial support [14].

Table 1 illustrates the different levels of power-over and power-with and interventions in moving to the extremes to address obesity.

Table 1. Moving to the extremes to address obesity.

\begin{tabular}{ccc}
\hline & & \\
\hline Community-centred & Lifestyle/behavioural & Regulation/legislation \\
Bottom-up (power-with) & Middle-ground & Top-down (power-over) \\
\hline
\end{tabular}

Traditionally, people have not been involved in identifying their own needs in regard to the determinants of health and in actively participating in large public health programs [15]. It has been the health worker that has controlled the design and delivery of the program even though there is evidence to suggest that community-wide actions can help prevent people from becoming obese and can help them to lose weight [16]. Community-centred interventions are about mobilising assets within communities, promoting equity, and increasing people's control over their health and lives. A policy template for countries to use practical, evidence-based options to improve community-centred interventions can bring a positive return on investment in approaches that strengthen communities, provide a role for peer and volunteer activities, develop partnerships, and provide better access to community resources [17]. The Altogether Better Project in the UK is an example of such a collaborative partnership to build capacity to empower communities to improve their own health and well-being [18].

Moving to the extremes means the planning and coordination of strategies that firmly place an equal emphasis on top-down (policy, regulation, and taxation) and bottom-up (local actions, self-help 
groups, volunteerism) interventions. There is still an important role for communication and behaviour change interventions (the middle-ground) to raise awareness and to motivate people to manage their lifestyle to maintain a healthy weight. However, in the future governments must use their power-over to take greater control and move to the extremes of top-down and bottom-up approaches. Bringing the public with them when using more stringent top-down interventions will be crucial to success. The agencies involved, including government services, the private sector, and communities, will therefore have to work together to help develop a supportive framework to implement obesity prevention strategies at a local and at a national level.

Funding: This research received no external funding.

Conflicts of Interest: The author declares no conflict of interest.

\section{References}

1. World Health Organisation. Obesity and Overweight: Fact Sheet. Available online: http://www.who.int/ news-room/fact-sheets/detail/obesity-and-overweight (accessed on 5 July 2017).

2. Wang, C.; McPherson, K.; Marsh, T.; Gortmaker, S.; Brown, M. Health and economic burden of the projected obesity trends in the USA and the UK. Lancet 2011, 378, 815-825. [CrossRef]

3. Laverack, G. Public Health: Power, Empowerment \& Professional Practice, 3rd ed.; Palgrave Macmillan: London, UK, 2016.

4. Gangolli, L.; Duggal, R.; Shukla, A. (Eds.) Review of Health Care in India; CEHAT: Mumbai, India, 2005.

5. Bernier, N. Health promotion program resilience and policy trajectories: A comparison of three provinces. In Health Promotion in Canada: Critical Perspectives; O'Neill, M., Ed.; Canadian Scholars' Press Inc.: Toronto, ON, Canada, 2007.

6. Laverack, G. The Pocket Guide to Health Promotion; Chapter 6; McGraw-Hill: London, UK, 2014.

7. Labonte, R.; Laverack, G. Health Promotion in Action: From Local to Global Empowerment; Palgrave MacMillan: London, UK, 2008.

8. Salas, X.R. The ineffectiveness and unintended consequences of the public health war on obesity. Can. J. Public Health 2015, 106, e79-e81.

9. Baum, F. Cracking the nut of health equity: Top down and bottom up pressure for action on the social determinants of health. Promot. Educ. 2007, 14, 90-95. [CrossRef] [PubMed]

10. Saskatoon Regional Health Authority. Saskatoon 'In Motion': Five Years in the Making; Saskatoon Regional Health Authority: Saskatoon, SK, Canada, 2005.

11. Arndt Andersen, H. Breakfast: A History; AltaMira Press: Lanham, MD, USA, 2013.

12. Flynn, M.; McNeil, D.; Maloff, B.; Mutasingwa, D.; Wu, M.; Ford, C.; Tough, S. Reducing obesity and related chronic disease risk in children and youth: A synthesis of evidence with 'best practice' recommendations. Obes. Rev. 2006, 7 (Suppl. 1), 7-66. [CrossRef] [PubMed]

13. Köhler, K.; Eksin, M.; Peil, E.; Sammel, A.; Uuetoa, M.; Villa, I. Policy Brief: Reducing the Consumption of Sugar-Sweetened Beverages in Estonia (World Health Organization EVIPNet Initiative); World Health Organization, Regional Office for Europe: Copenhagen, Denmark, 2016.

14. Laverack, G. Health Promotion Practice: Power \& Empowerment; SAGE Publications: London, UK, 2004.

15. South, J.; White, J.; Gamsu, M. People-Centred Public Health; Policy Press, University of Bristol: Bristol, UK, 2013.

16. National Institute for Health and Care Excellence (NICE). Obesity: Working with Local Communities; Public Health Guideline, PH42; National Institute for Health and Care Excellence: London, UK, 2017.

17. Public Health England. A Guide to Community-Centred Approaches for Health and Well-Being; Report Number 2014711; Public Health England: London, UK, 2015.

18. Giuntoli, G.; Kinsella, K.; South, J. Evaluation of the 'Altogether Better' Asset Mapping in Sharrow and Firth Park, Sheffield; Leeds Metropolitan University, Institute for Health and Wellbeing: Leeds, UK, 2012. 